\title{
Os Valores da Geodiversidade de Acordo com os Serviços Ecossistêmicos Sensu Murray Gray Aplicados a Estudos In Situ na Cidade do Natal (RN)
}

\author{
Geodiversity' Values According to the Ecosystem Services Sensu Murray Gray \\ Applied to In Situ Studies in the City of Natal (RN)
}

\author{
Matheus Lisboa Nobre da Silva \\ Geólogo pela UFRN e Técnico em Geologia e Mineração pelo \\ Insituto Federal de Educação, Ciência e Tecnologia do Rio Grande do Norte \\ nobre.mt@gmail.com \\ Marcos Antonio Leite do Nascimento \\ Professor Adjunto do Departamento de Geologia Universidade Federal \\ do Rio Grande do Norte \\ marcos@geologia.ufrn.br
}

\begin{abstract}
Resumo
A geodiversidade do planeta é compreendida por todos os recursos abióticos que compõem a natureza: solos, minerais, rochas, rios, lagoas, paisagens e fenômenos naturais como o intemperismo e magmatismo. A partir disto, pesquisadores têm focado seus estudos, sob esta nova óptica das geociências, desde a década de 1990, se aproveitando também da multidisciplinaridade permitida pela geodiversidade e divulgando os conteúdos geológicos pela sociedade. Em Natal, capital do Rio Grande do Norte, a geodiversidade está presente nas belas paisagens, compostas por praias, dunas, falésias, rios, mangues e lagoas. Ao longo de toda a história da cidade, que perpassa mais de 400 anos, a geodiversidade mostra-se sempre presente, desde os primórdios da cartografia local, que remonta ao período de ocupação holandesa, em que o ambiente natural fora retratado fidedignamente. Os estudos desenvolvidos neste trabalho abordam a geodiversidade da cidade do Natal que ocorre de forma natural, in situ, na região da cidade. São feitas descrições dos valores da geodiversidade, de acordo com os serviços ecossistêmicos, como definidos por Murray Gray.
\end{abstract}

Palavras-chave: Geodiversidade, Valoração Qualitativa, Murray Gray, Rio Grande do Norte

\begin{abstract}
Geodiversity of the planet is understood by all abiotic resources that make up the nature: soils, minerals, rocks, rivers, lakes, landscapes and natural phenomena such as weathering and magmatism. From this, researchers have focused their studies under this new perspective of geosciences since the 1990s, also taking advantage of the multidisciplinary allowed by geodiversity and disseminating the geological content through the society. In Natal, capital of Rio Grande do Norte, the geodiversity is represented by the beautiful landscapes composed by beaches, dunes, cliffs, rivers, wetlands and lakes. Throughout the history of the city, running through more than 400 years, geodiversity is present since the beginning of the local mapping, dating back to the Dutch occupation period, in which the natural environment was portrayed faithfully. The studies developed in this work addresses the geodiversity of Natal that occurs naturally, in situ, in the city's region. Descriptions of the geodiversity values are made, according to ecosystem services, as defined by Murray Gray.
\end{abstract}

Keywords: Geodiversity, Qualitative Evaluation, Murray Gray, Rio Grande do Norte 


\section{INTRODUÇÃO}

A partir do desenvolvimento dos conceitos de geodiversidade, geoconservação e geoturismo, a comunidade geocientífica passou a pensar e criar projetos de estudo e proteção do meio abiótico, objetivando que sua exploração possa ser, em muitos casos, realizada de forma mais sustentável.

Dessa forma também começaram a ser desenvolvidos, sob esta ótica e com mais intensidade, trabalhos de divulgação das geociências, da história da Terra e da importância dos elementos naturais, geológicos, para a vida no planeta. Admite-se hoje que conhecer a moradia de todas as formas de vida biótica é tão fundamental quanto conhecer a biodiversidade em si, é fundamental, portanto, conhecer o meio que dá suporte à vida no planeta, que é conhecido por geodiversidade.

O horizonte desvendado pelos estudos da geodiversidade nos centros urbanos permite uma relação direta da sociedade com as geociências, sendo ferramenta importante na divulgação das ciências da Terra.

Uma vez que as cidades foram instaladas em locais cuja geodiversidade favorecia o seu erguimento, principalmente pela disponibilidade de recursos naturais, é imprescindível que o processo de entendimento da urbis compreenda também o seu ambiente, o que engloba a geodiversidade.

Com esta visão, este trabalho pretende identificar os principais valores da geodiversidade na cidade do Natal, maior município do Rio Grande do Norte, sendo também a capital potiguar. Sua fundação no final do século XVI esteve atrelada à necessidade portuguesa de domínio das terras brasileiras. A posição geográfica da cidade foi fundamental para a expansão do poder de conquista do reino português para o interior do continente. Tal fato tem relação com a geologia e geomorfologia dessa região, que foram suportes para o desenvolvimento da cidade.

Até o momento, os poucos trabalhos que versaram sobre a geodiversidade na cidade do Natal não focaram em sua geodiversidade in situ, ou seja, aquela que encontra-se em seu local natural de ocorrência. Contudo, a geodiversidade utilizada nas edificações, monumentos e ruas, sobretudo do centro histórico, já foram exploradas por projetos de pesquisa, extensão e de conclusão de curso.

O sistema de valoração aqui aplicado foi estabelecido no trabalho de Gray (2013), a partir de uma atualização que este autor fez de seu primeiro sistema de valores da geodiversidade, hoje um dos mais utilizados no mundo. Essa atualização se baseou na Avaliação Ecossistêmica do Milênio, uma associação de milhares de cientistas que estabeleceram, a pedido na ONU, parâmetros para as 
avaliações dos ecossistemas, à época voltadas principalmente para a biodiversidade, que Gray adaptou para incluir a geodiversidade, devido à sua clara importância.

\section{SERVIÇOS ECOSSISTÊMICOS DA GEODIVERSIDADE}

Geodiversidade representa o universo dos elementos abióticos do meio ambiente - como minerais, rochas, solos, águas, paisagens, entre outros - que compõem a diversidade natural do planeta, sendo a base do desenvolvimento da biodiversidade na Terra. Os estudos norteados por essa terminologia tiveram início apenas na década de 1990 e ainda são desconhecidos do público leigo, como também de diversos profissionais que realizam pesquisas na área das geociências.

Os trabalhos de Brilha (2005) e Galopim de Carvalho (2007) mostram a relação intrínseca entre as sociedades humanas e a geodiversidade, tendo sido esta de uso fundamental desde a Idade da Pedra, quando o sílex era utilizado para a caça. De fato, as condições naturais dos ambientes definiram até mesmo, ao longo dos séculos, as formas e locais de ocupação do ser humano, assim as cidades mercantilistas se favoreceram das zonas de costa para facilitar a atividade marítima, relação modificada pela Revolução Industrial e com as necessidades por minerais metálicos, mais facilmente encontrados no interior dos continentes.

A biodiversidade, por sua vez, está condicionada aos processos abióticos (BRILHA, 2005), aqui tratados como processos da geodiversidade, o que se prova pelo seu desenvolvimento ao longo do Tempo Geológico, que só se iniciou com o processo de consolidação da crosta terrestre, no início do Proterozoico.

Ou seja, é possível estudar a geodiversidade juntamente com os estudos sobre o homem, além de ser, ao mesmo tempo, impossível dissocia-la dos estudos da natureza, sobretudo daqueles que tenham enfoque principal a conservação da natureza, em suas características abióticas, de forma a promover um consumo sustentável dos recursos naturais.

Uma vez que as ações de proteção do meio ambiente estão vinculadas à definição de valores que hierarquizem os lugares de maior necessidade de proteção, seja por serem lugares de extrema beleza ou por terem importância para os ecossistemas regionais ou mundiais, os locais em que a geodiversidade está presente também têm valores que precisam ser definidos pelas pessoas que trabalham com tal enfoque, de forma a fundamentar as estratégias de geoconservação, como indica Brilha (2005).

Um dos primeiros trabalhos que definiu um sistema de valores para a geodiversidade foi o de Gray (2004), no qual o autor determinou 6 valores e 32 subvalores para os elementos abióticos da natureza. Esta proposta tornou-se, ao longo da última década, uma das mais utilizadas em todo o 
mundo. No Brasil, são exemplos de aplicação dessa abordagem os trabalhos de Pereira (2010) e Mochiutti et al. (2011, 2012). Atualmente, contudo, tem-se destacado na literatura especializada o sistema de valores da geodiversidade com base nos serviços ecossistêmicos, indicados pela Natural England (2006) como uma forma de descrever a contribuição da natureza para a qualidade de vida no planeta, promovendo uma boa relação entre os estudos da geodiversidade com os da biodiversidade. Assim, Fisher et al. (2009) definem esses serviços como os "aspectos do ecossistema utilizados (ativa ou passivamente) para produzir o bem-estar humano".

Gray (2013) definiu, a partir da Avaliação Ecossistêmica do Milênio, um novo sistema de valoração para a geodiversidade, composto por 1 valor (intrínseco), 5 serviços (regulação, suporte, provisão, cultural e conhecimento) e 25 bens e processos.

O valor intrínseco é também conhecido por valor de existência. "Refere-se à crença ética de que algumas coisas possuem valor simplesmente pelo que elas são, mais do que para o que elas podem ser usadas pelo homem" (GRAY, 2013). É um valor bastante debatido, até mesmo contestado por alguns especialistas da área, porque possui muita subjetividade em sua avaliação, afinal há um ponto ético associado, que pode mudar de acordo com a comunidade local. Mesmo assim, o sistema de Murray Gray indica que apenas por existir, um elemento da geodiversidade já possui seu valor.

O serviço de regulação da geodiversidade compreendem os processos que têm por finalidade o controle natural das condições ambientais, seja do ar, da água e dos solos. Controla a disponibilização destes recursos, sua quantidade e qualidade. São compreendidos pelo serviço de regulação os processos atmosféricos e oceânicos, o ciclo hidrológico e a química atmosférica, além de processos terrestres, como o ciclo do carbono, controle de inundação e qualidade da água.

Os serviços de suporte são aqueles em que a geodiversidade dispõe de recursos para o desenvolvimento de atividades do ser humano ou da própria natureza, e que dependam diretamente dos solos e rochas para serem realizadas. Compreende a disponibilização de recursos para algumas atividades do homem e da biota do planeta.

Processos do solo, como desenvolvimento de perfis pedológicos, disponibilização de habitat, plataforma, além de sepultamento e armazenamento são processos e bens naturais relativos ao serviço de suporte da geodiversidade.

Este tipo de serviço de provisão da geodiversidade é responsável por disponibilizar bens materiais para as sociedades humanas, é o de mais fácil compreensão porque, na maioria dos casos, possui um valor monetário associado ao bem, que passa a ser tratado como produto. Compreende 7 bens que são descritos abaixo.

São bens e processos relativos ao serviço de provisão: alimentação e bebida, nutrientes e minerais para crescimento saudável, combustíveis minerais, materiais de construção, minerais 
industriais e metálicos, gemas e fósseis. Apesar de na Europa a comercialização de fósseis ser permitida, a legislação brasileira impede este tipo de atividade, assim é preciso fazer observação a esta diferença no momento de aplicação do sistema.

O serviço cultural está relacionado com a relação da sociedade a algum aspecto abiótico do ambiente por seu significado social ou comunitário. A seguir estão descritas as 5 atividades relacionadas a este serviço da geodiversidade.

São processos e bens do serviço cultural: qualidade ambiental, que refere-se ao apelo estético das paisagens, além de geoturismo e atividades de lazer, significado cultural, espiritual e histórico, inspiração artística e desenvolvimento social.

O serviço de conhecimento. Provavelmente o tipo de serviço mais importante, sobretudo para as geociências, está relacionado com propostas de utilização da natureza abiótica como sala de aula e laboratório, sendo sua exploração puramente científica e educacional. Seguem abaixo a descrição das 5 expressões deste tipo de serviço.

História da Terra, história da pesquisa, monitoramento ambiental, geoforense e educação e emprego são bens e processos relacionados ao serviço de conhecimento.

Silva (2016) sumarizou o sistema dos serviços ecossistêmicos da geodiversidade sensu Murray Gray no diagrama da figura 1. 


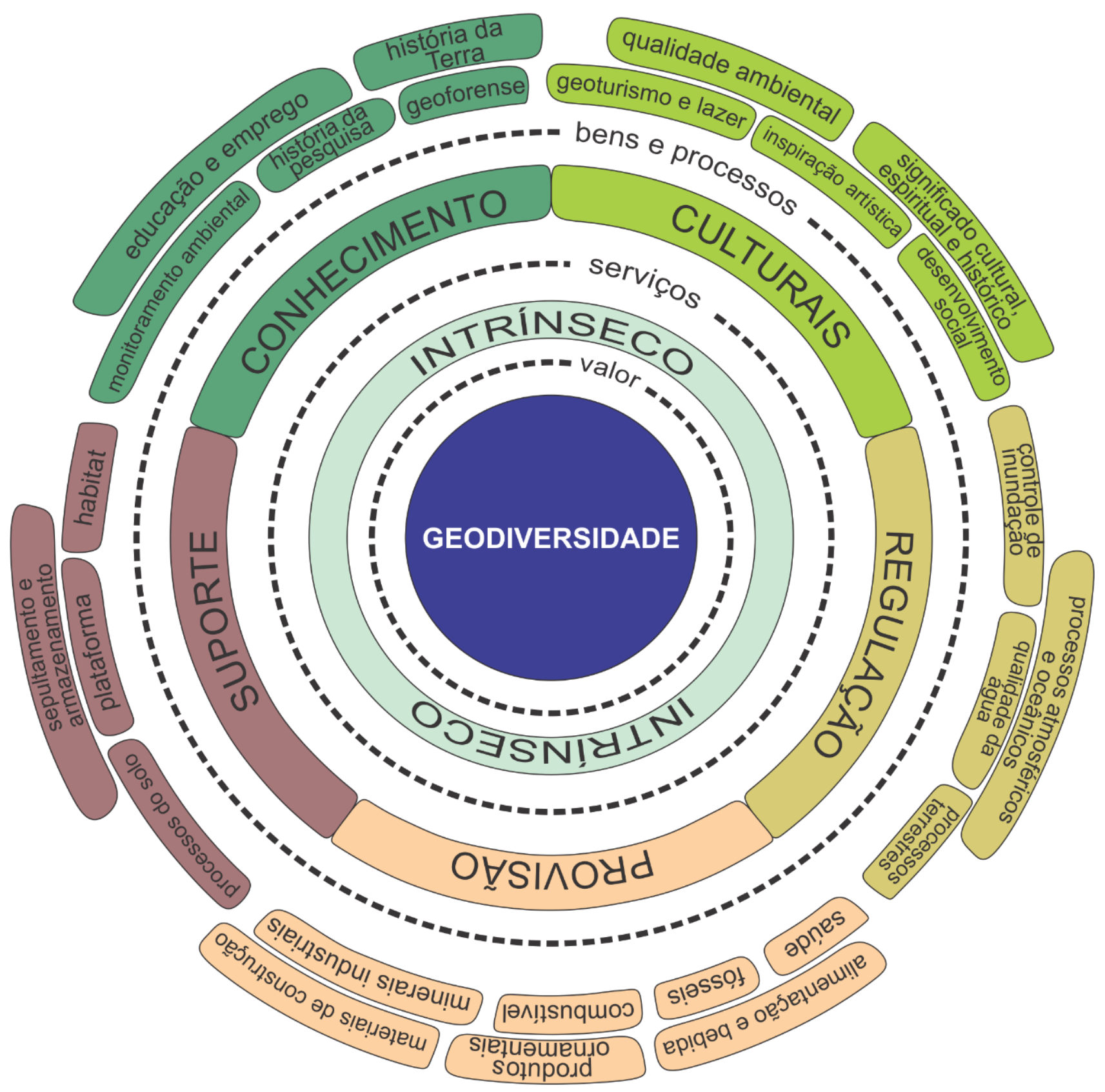

Figura 1 - Diagrama simplificado do sistema de valores da geodiversidade de acordo com os serviços ecossistêmicos sensu Murray Gray

Fonte: Silva, 2016

\section{3. ÁREA DE ESTUDO}

A cidade de Natal está localizada na costa leste do estado do Rio Grande do Norte, no Nordeste brasileiro. É dividida, administrativamente, em 4 zonas (norte, sul, leste e oeste), possuindo 36 bairros. É limitada a norte pelo município de Extremoz, a oeste pelos municípios de São Gonçalo do Amarante e Macaíba, a sul pelo município de Parnamirim e a leste pelo Oceano Atlântico. Os acessos principais se dão por via rodoviária, pelas BR-101, BR-304, BR-226 e BR406, por via aérea, através do Aeroporto Internacional Aluísio Alves, ou por via marítima, através 
do Porto de Natal. O mapa da figura 2 apresenta a localização da cidade, área de estudo deste trabalho, e suas principais vias de acesso.

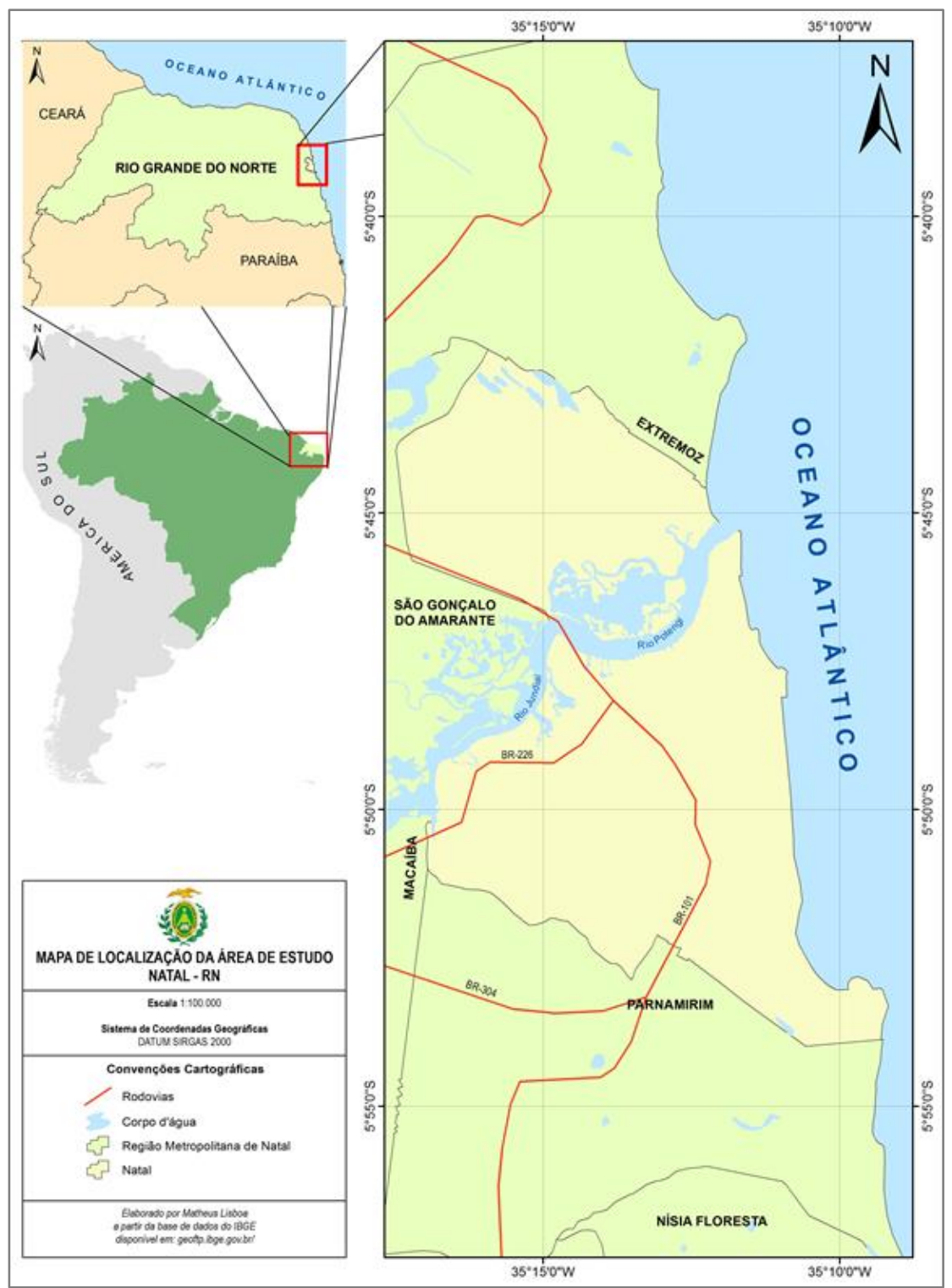

Figura 2 - Mapa de Localização da Cidade do Natal

\subsection{Aspectos geológicos regionais}

A região onde se localiza a cidade do Natal é compreendida, geologicamente, pelo segmento meridional da Província Costeira (figura 3), definida por Almeida et al. (1977). É representada por rochas sedimentares de idade Cretácea, cobertas pela Formação Barreiras e por depósitos sedimentares, aluvionares a litorâneos praiais. O embasamento cristalino da região é correlato ao domínio setentrional da Província Borborema.

Entende-se que a porção do litoral brasileiro onde está a capital potiguar faz parte do domínio da Bacia Pernambuco-Paraíba, uma bacia do tipo rifte, subdividida em duas 
Supersequências, uma Rifte e outra Drifte. Sua formação está associada ao evento de rifteamento do Atlântico Sul, que culminou com a abertura final do Oceano Atlântico e separação dos continentes Africano e Sul-Americano, ainda no processo de ruptura do supercontinente Gondwana, no final do Aptiano (CÓRDOBA et al., 2007).

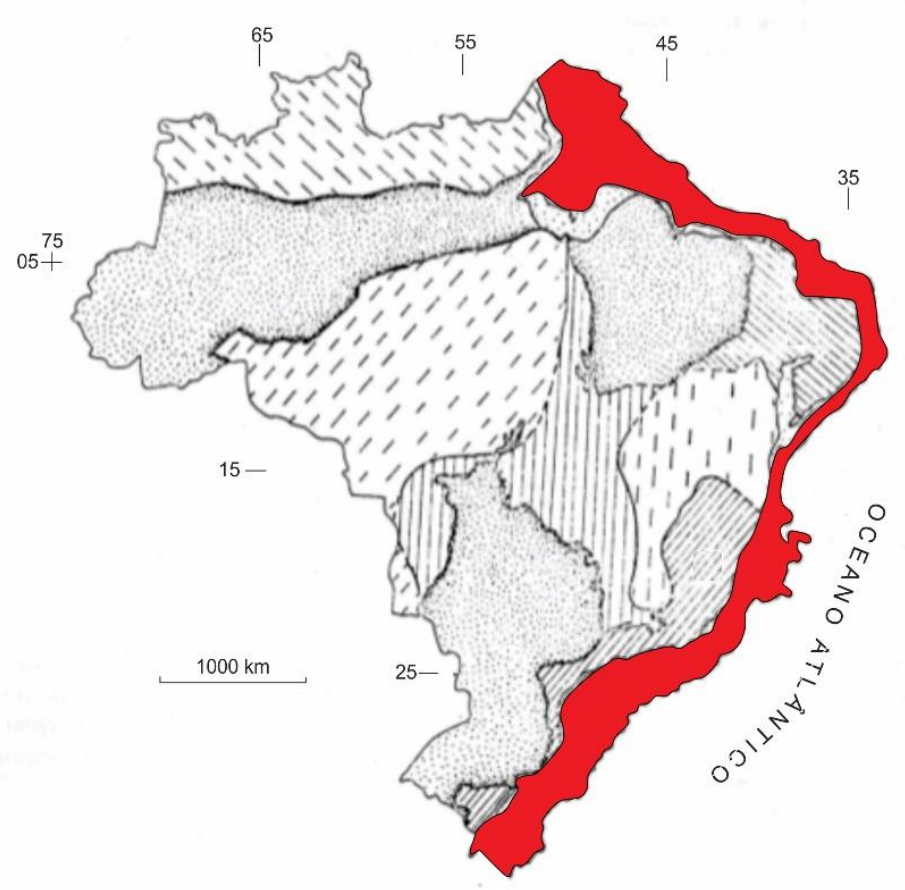

Figura 3 - Províncias Estruturais Brasileiras. Destaque em vermelho para a Província Costeira, onde está localizada a área de estudo deste trabalho, no extremo nordeste do Brasil.

Fonte: Modificado de Almeida et al. (1977)

A bacia Pernambuco-Paraíba apresenta um significativo alinhamento estrutural E-W que é responsável pelo controle tectônico das bacias mesozoicas (MOHRIAK, 2003). É capeada, principalmente, nas partes mais proximais, por sedimentos de leques aluviais e fluviais da Formação Barreiras.

Admite-se a compartimentação da bacia em duas: bacia Pernambuco a sul e bacia Paraíba a norte, que é o domínio da região de Natal, como mostra o trabalho de Barbosa e Lima Filho (2005). O controle estrutural em ambas é semelhante e o marco divisor entre as duas é a Zona de Cisalhamento Pernambuco.

\subsection{Geologia e Geomorfologia Local}

Especificamente na área de estudo deste trabalho, são aflorantes apenas sedimentos e rochas sedimentares do Cenozoico, como a Formação Barreiras, depósitos marinhos, continentais, 
aluvionares, eólicos continentais, eólicos litorâneos (vegetados ou não), flúvio-marinhos e litorâneos praiais. Também são bastante evidentes ao longo do litoral natalense, diversos corpos de recifes arenosos.

Dantas e Ferreira (2010) mostram que os principais padrões regionais de relevo da região costeira onde se situa Natal são os campos de dunas, as planícies flúvio-marinhas e os tabuleiros costeiros.

Destes, as dunas apresentam-se sobrepondo os tabuleiros costeiros, formados por rochas sedimentares neógenas correlatas à Formação Barreiras. Já as planícies flúvio-marinhas correspondem aos manguezais e encontrados em algumas das principais cidades potiguares.

Melo (2013) indica que as feições geomorfológicas que estão presentes na capital potiguar são: corpos d'água, planície de inundação fluvial, planície flúvio-marinha, praias, tabuleiros costeiros e dunas, fixas e móveis, sendo esta última feição dominante na paisagem local.

Muitas dessas feições foram modificadas pela ocupação urbana no município, que provocaram descaracterização de campos de dunas, aterramento da planície estuarina, alterações da rede de drenagem, redesenhando bacias hidrográficas (MELO, 2013).

\section{PRINCIPAIS VALORES DA GEODIVERSIDADE IN SITU EM NATAL}

A geodiversidade é representada por todos os componentes da natureza abiótica, como minerais, rochas, solos, rios, paisagens e as relações e processos naturais envolvidos por esses recursos. Está presente, portanto, em todos os ambientes do planeta, ocorrendo nas mais diversas formas e extensões.

$\mathrm{Na}$ cidade do Natal, a geodiversidade, em sua expressão in situ, é encontrada, principalmente, sob a forma de zonas de praias, campos de dunas, manguezais e rios.

\subsection{Praias}

Natal possui um vasto litoral, com mais de $17 \mathrm{~km}$ de extensão, compreendendo 7 praias, de norte a sul: Redinha, Forte, Meio, Artistas, Areia Preta, Via Costeira e Ponta Negra. Ambas são caracterizadas como praias arenosas.

Ao longo do litoral natalense é possível encontrar, geologicamente, depósitos eólicos litorâneos vegetados e não-vegetados, depósitos litorâneos praiais, recifes arenosos que são encontrados submersos, na região de shoreface, distantes da face da praia, e regiões de backshore com intenso adensamento urbano. 
Apesar de dispor de diversas praias, o cidadão natalense só começou a usufruir delas a partir do século XX. Souza (2008) aponta que, inicialmente, apenas a elite da cidade costumava frequentar as praias, distantes do centro da cidade para os padrões da época. Assim, começavam a serem frequentadas as praias de Areia Preta no começo do século, seguida das praias do Meio e da Redinha na década de 1920. O uso da praia de Ponta Negra, hoje a mais famosa, teve início apenas na década de 1940.

As praias são fundamentais para o ecossistema, pois além de representarem a linha de costa, aonde a relação entre continente e oceano é mais intensa, são locais necessários para a vida de algumas espécies de invertebrados, assim como são os principais lugares de lazer do ser humano, sobretudo em países como o Brasil, que possuem extensa área litorânea.

Em relação aos valores da geodiversidade definidos por Gray (2013), nas praias de Natal são identificados, além de um valor intrínseco, devido à simples existência dos recursos abióticos, os serviços de regulação, suporte, cultural e de conhecimento.

O serviço de regulação é caracterizado devido à presença de processos terrestres, que são responsáveis pela modelagem das feições da praia, por correntes marítimas, por exemplo, e pela presença dos recifes de arenitos que servem, especialmente na região das praias do Forte, Meio e dos Artistas, para o controle de inundação, protegendo a linha de costa e mitigando a invasão das águas marinhas.

O serviço de suporte é identificado na praia do Forte aonde os arrecifes serviram de plataforma sólida para a construção do Forte dos Reis Magos (figura 4), erguido no início do século XVII e principal monumento histórico da cidade. Também é possível identificar nas demais praias, pois os recursos abióticos, como rochas e solos, são utilizados como habitat de espécimes de bivalves, crustáceos, entre outros invertebrados.

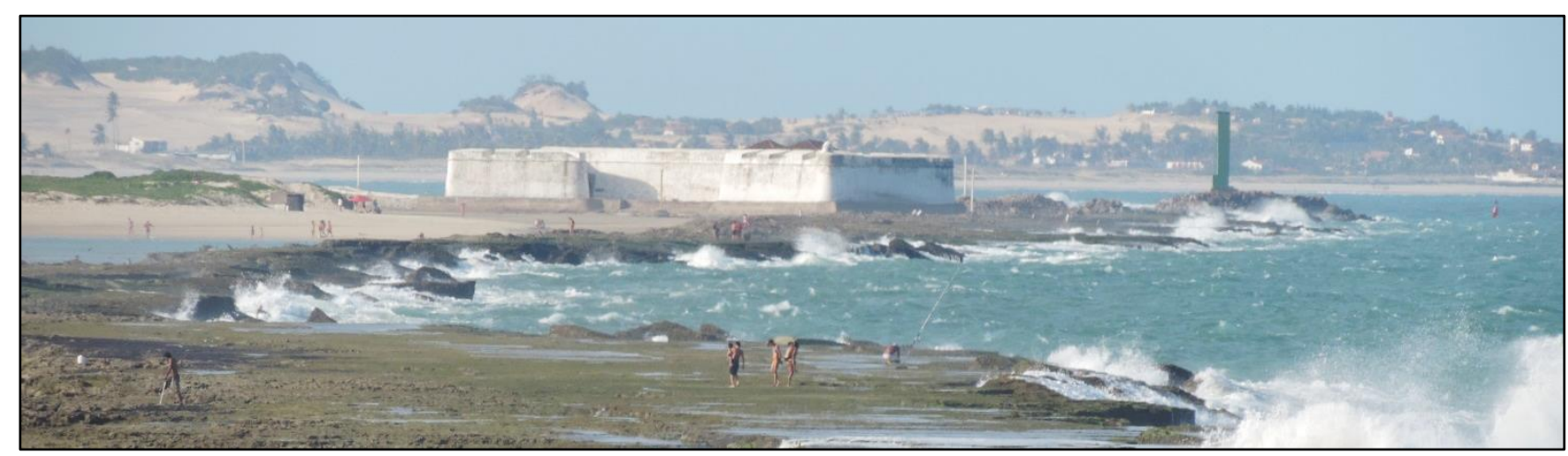

Figura 4 - Forte dos Reis Magos, praia do Meio (Natal - RN). Destaque para os corpos de arenitos praias sobre os quais a edificação foi construída no século XVII, serviço de suporte da geodiversidade.

Foto: Matheus Lisboa 
O serviço cultural é verificado nas praias de Natal pela estética de suas paisagens, o que caracteriza uma qualidade ambiental da geodiversidade. Atividades de lazer como o futebol nas areias das praias também caracterizam esse tipo de serviço ecossistêmico, assim como o uso das paisagens das praias como inspiração artística para a criação de quadros, poesias, músicas e qualquer outra expressão artística. Ações voluntárias de proteção ao meio ambiente caracterizam um desenvolvimento social por meio da geodiversidade, o que ocorre, por exemplo, na praia da Redinha através do projeto "Amigo da Praia".

O serviço de conhecimento é justificado por trabalhos como os de Barreto et al. (2004) e Cunha (2004), além de atividades que desenvolvem trabalhos de pesquisa, ensino e extensão nas praias de Natal, visando o fomento da educação e emprego no que se refere ao uso dos recursos abióticos disponíveis nas praias, e o monitoramento ambiental das praias como faz o "Programa Água Azul" por meio de estudos de balneabilidade nas praias urbanas de Natal e de outros municípios do estado. No caso do Litoral Central, datações ${ }^{14} \mathrm{C}$ feitas por Oliveira et al. (1990) e Barreto et al. (2004) em conchas nos arenitos praiais da região colaboraram com o mapeamento do Holoceno no Rio Grande do Norte determinando uma idade de cerca de 4000 anos AP, o que caracteriza um processo de escrita da história da Terra.

\subsection{Campos de dunas}

As dunas são, juntamente com as praias, as principais feições geomorfológicas na paisagem de Natal. São classificadas, geologicamente, por Fonseca et al. (2012), na Folha Natal, escala 1:100.000 (Serviço Geológico do Brasil - CPRM), como Depósitos Eólicos Vegetados e NãoVegetados. Há um predomínio de ocorrências de dunas tipo parabólica, em planta.

Corpos dunares de extensões consideráveis estão presentes nas quatro zonas administrativas da cidade, como também constituem os dois principais parques naturais locais, Parque das Dunas (figura 5) e Parque da Cidade, os principais corpos remanescentes são protegidos por Zonas de Proteção Ambiental.

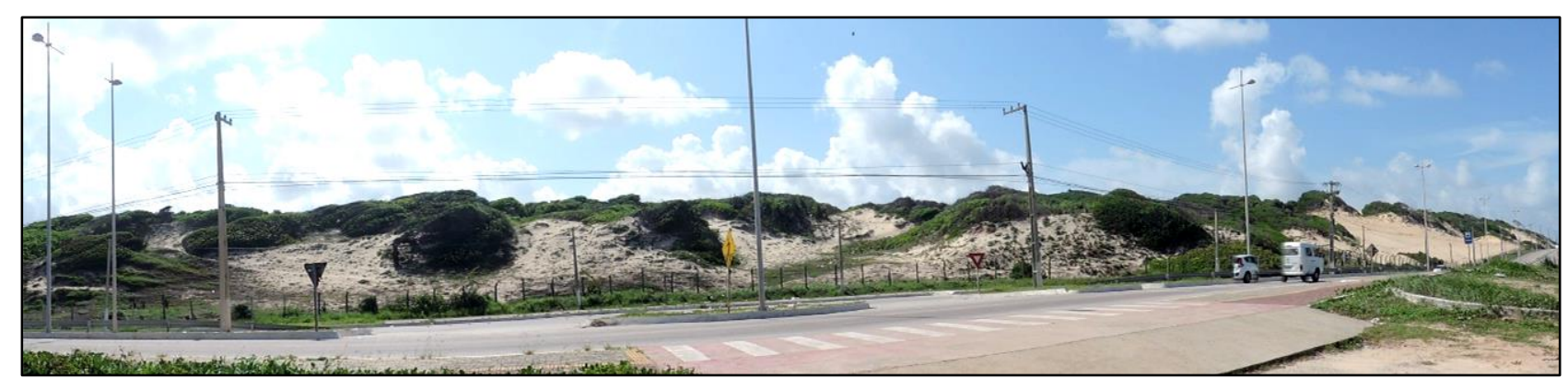

Figura 5 - Trecho do campo de dunas do Parque das Dunas.

Foto: Matheus Lisboa 
A principal variação nos corpos se dá nas cores dos sedimentos, variando de avermelhado a esbranquiçado. Isso se dá devido à presença ou não de óxido de ferro capeando os grãos de quartzo e de matéria orgânica. Em todas as regiões, as areias das dunas são quartzosas bem selecionadas.

Em relação aos valores da Geodiversidade, como definidos por Gray (2013), os campos de dunas da cidade do Natal possuem, além de um valor intrínseco, devido à sua própria existência, os serviços de regulação, suporte, provisão, cultural e de conhecimento.

O serviço de regulação é observado nos campos de dunas devido à sua importância para a infiltração de água no lençol freático local, recarregando os aquíferos e fazendo parte do ciclo hidrológico, o que caracteriza um processo atmosférico, ao mesmo tempo que controla a qualidade da água, funcionando como um filtro para o armazenamento de água no subsolo.

O serviço de suporte é justificado por as dunas serem potenciais fornecedores de sedimentos eólicos que podem vir a compor os perfis pedológicos em suas vizinhanças, caracterizando a sua importância para os processos do solo. Especificamente, o campo de dunas localizado na região leste da cidade também serve como plataforma, uma vez que o Farol de Mãe Luísa foi sobre ele construído. Na maioria dos campos de dunas, há presença de algumas espécies vegetais que, por utilizarem o substrato dunar para sua fixação e desenvolvimento, fazem dele seu habitat.

O serviço de provisão é identificado pela importância das dunas na disponibilização de água doce no lençol freático que pode ser bebida, no caso de não haver poluição no aquífero.

O serviço cultural é percebido de forma mais concreta no campo de dunas da região sul da cidade, em especial, devido à existência do Morro do Careca, que imprime na paisagem uma beleza única, que define certa qualidade ambiental ao espaço, servindo também como inspiração artística, sobretudo para pinturas, artesanato em geral e fotografias. Atividades voluntárias de proteção ao Morro do Careca, tanto em relação à sua imponência na paisagem local como na sua proteção agregam um desenvolvimento social.

O serviço de conhecimento é exemplificado por projetos que almejam a difusão das geociências pela educação, como o Projeto Monumentos Geológicos do Estado do Rio Grande do Norte, no qual o Morro do Careca é um dos pontos sinalizados com informações geocientíficas traduzidas para o público leigo, visando sua conservação.

\subsection{Manguezais}

Os mangues na cidade do Natal são encontrados no estuário do Rio Potengi, em suas duas margens. Constituem a Zona de Proteção Ambiental 8, conforme o Plano Diretor vigente (LEI COMPLEMENTAR No 082/2007). 
São entendidos, geologicamente, como depósitos flúvio-marinhos, constituídos por areias finas, siltes e argilas, cuja laminação é fina. Sua composição é rica em carbonato e matéria orgânica. Os mangues são fontes de alimentação, refúgio e reprodução de várias espécies de crustáceos e peixes.

Ao longo dos anos, muitas áreas de mangue em Natal foram devastadas para dar lugar a criatórios de camarão e antigas salinas. Com isso, a área total hoje protegida pela ZPA-08 é, aproximadamente, $50 \%$ da original.

Entretanto, algumas iniciativas fazem uso do mangue de forma cultural e mais sustentável, como o Bloco "Os Cão", que desde 1964 promove um desfile na terça-feira de carnaval em que todos usam a lama do mangue no corpo como fantasia (figura 6). A lama, um recurso abiótico da natureza, passa a ter, portanto, uma expressão cultural em tempos carnavalescos.

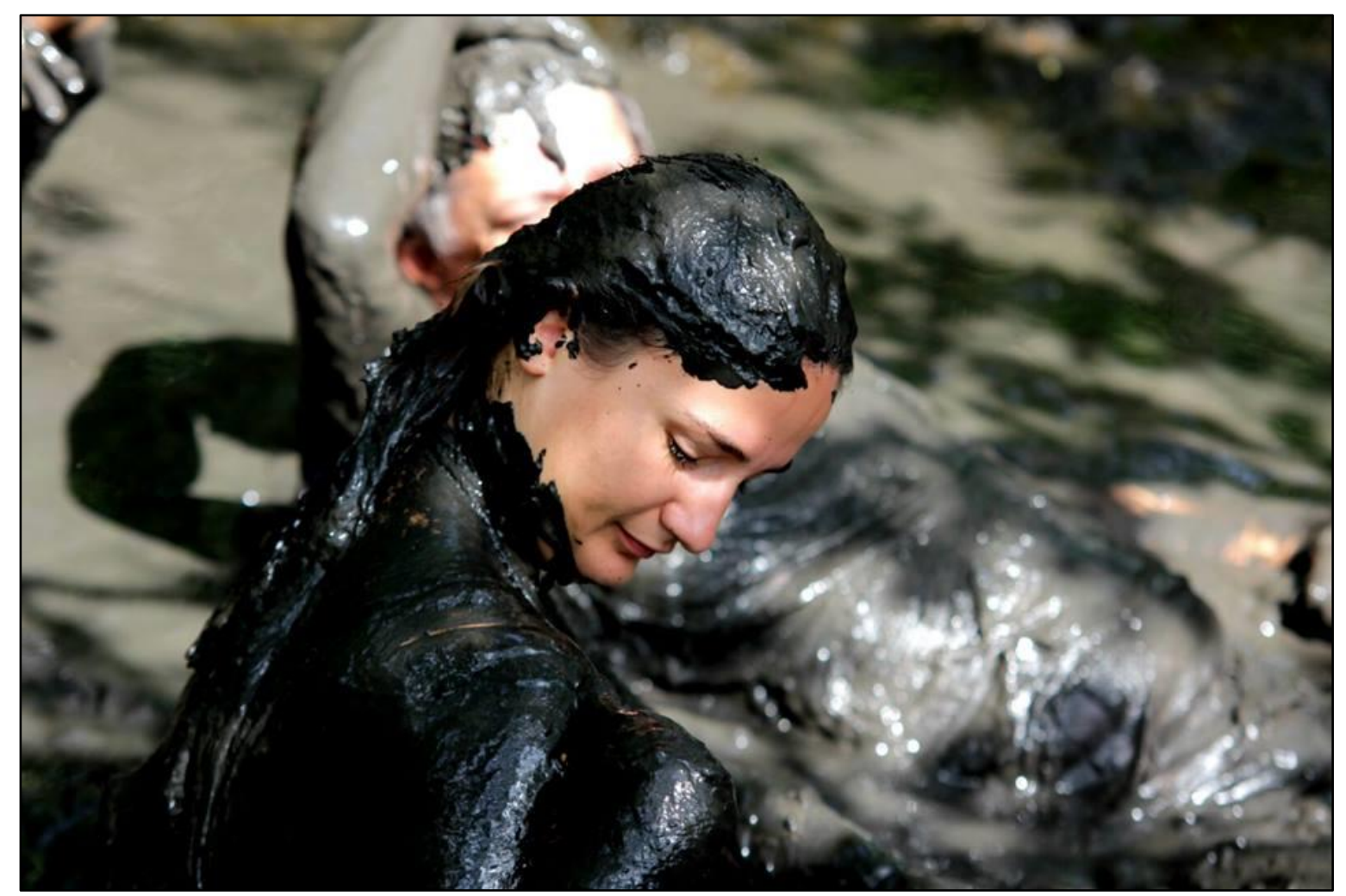

Figura 6 - Foliã passando lama do mangue no corpo, este é o "abadá” do Bloco dos Cão na Redinha. Foto: Alex Régis / Tribuna do Norte

Quando é feita a valoração da geodiversidade nos manguezais de Natal a partir das definições de Gray (2013), pode-se afirmar que, além do valor intrínseco, é possível identificar apenas os serviços de suporte e cultural.

O serviço de suporte é identificado pelo mangue ser habitat para várias espécies de animais e serviu de plataforma para a construção das fazendas de camarão e salinas. 
O serviço cultural é justificado porque, a exemplo do "Bloco dos Cão", o mangue passou a ter um significado cultural para algumas pessoas, em especial em períodos carnavalescos.

\subsection{Rios}

Três rios principais banham a cidade do Natal e são responsáveis por abastecer a maior parte da população local, fornecendo águas superficiais ao sistema de abastecimento, como complemento das águas subterrâneas. São os três: Doce, Pitimbu e Potengi. Ambos são classificados como perenes, o que é justificado por uma descarga boa e constante ao longo do ano. São componentes do Aquífero Barreiras, principal da região costeira do Rio Grande do Norte.

Bezerra et al. (2001) mostram que há um evidente controle estrutural sobre os cursos destes três rios, cujas origens são relacionadas a conjuntos de falhamentos que formaram vales estruturais.

Principal rio da cidade e um dos maiores do estado do Rio Grande do Norte, o Rio Potengi nasce na cidade de Cerro Corá e percorre $123 \mathrm{~km}$ até a sua foz no Oceano Atlântico, já na capital potiguar. Possui, ao longo de suas margens, várias áreas de manguezais.

O rio Potengi (figura 7) possui uma relação intrínseca com a história da cidade do Natal, está presente desde o início no cotidiano de muitos dos moradores e visitantes, através das pontes construídas sobre ele, a cidade está ligada. É ele que divide a zona norte, maior região administrativa da cidade, das demais. É também espaço de desenvolvimento econômico e lazer.

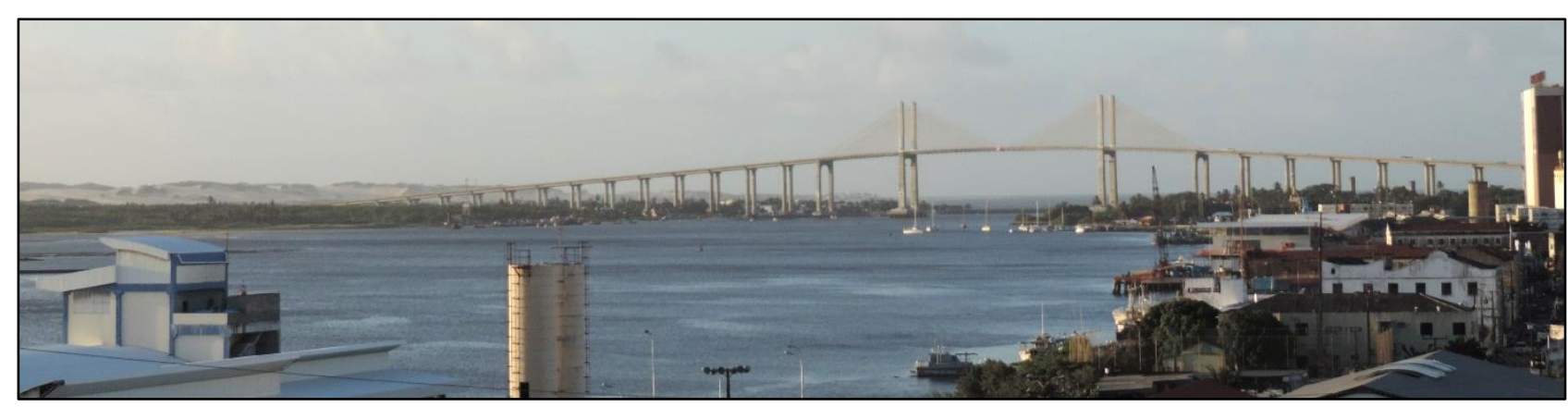

Figura 7 - Ao longo do Potengi, Natal cresceu e se desenvolveu, há, portanto, uma forte relação da cidade com este elemento da geodiversidade, que é o rio.

Foto: Matheus Lisboa

Atualmente em declínio, o remo foi, desde 1897, um dos principais esportes praticados em Natal, e era justamente no canal do rio Potengi que os atletas em seus barcos praticavam seus treinos e competições eram realizadas. Ainda hoje há sedes em funcionamento de clubes de regatas na rua Chile, bairro da Ribeira. 
Dos valores da geodiversidade definidos por Gray (2013), além do valor intrínseco, são identificados nos principais rios de Natal os serviços ecossistêmicos de regulação, suporte, provisão, cultural e de conhecimento.

O serviço de regulação é explicado devido à participação dos rios no ciclo hidrológico, o que caracteriza processos atmosféricos e oceânicos, corrobora com esse serviço o fluxo de água dos rios, sobretudo do rio Doce e Potengi, em direção ao oceano, influenciando o movimento de águas oceânicas na região.

O serviço de suporte é devido à presença de espécies de peixes e crustáceos que usam os rios como habitat.

O serviço de provisão ocorre porque estes rios são fundamentais para o abastecimento de água potável na cidade do Natal, através de suas relações com o aquífero Barreiras, disponibilizando-a para ser bebida.

O serviço cultural é identificado pela paisagem dos rios, que propiciam uma qualidade ambiental ao meio, assim como através das atividades de lazer que são realizadas nos cursos dos rios, com destaque à prática do remo no rio Potengi. Atividades voluntárias de proteção aos mananciais, como recolhimento de lixo nos rios caracterizam este serviço da geodiversidade através do desenvolvimento social.

O serviço de conhecimento está embasado na quantidade de trabalhos científicos que versam sobre os mananciais dos rios Doce, Pitimbu e Potengi, e que colaboram a formação, via educação, de profissionais que possam a vir trabalhar na área. Todos os rios são fundamentais em diversos estudos da dinâmica hidrogeológica local.

\section{CONSIDERAÇÕES FINAIS}

A geodiversidade, representando todos os elementos de natureza abiótica, está presente nos mais diversos ambientes no mundo, inclusive nos centros urbanos. Ela condicionou ao longo dos séculos até mesmo o desenvolvimento das cidades. Na cidade do Natal, a presença dos elementos da geodiversidade é também facilmente reconhecida, nas praias, dunas, rios e manguezais. Cada um desse tipo de ambiente mostra a predominância de elementos abióticos em sua constituição, o que demonstra a importância da geodiversidade na consolidação dos espaços naturais da cidade.

A avaliação da geodiversidade in situ na capital potiguar, a partir dos serviços ecossistêmicos, mostrou que todos os valores são possíveis de serem encontrados na cidade, apenas alguns bens e processos relacionados ao serviço de provisão, com valor monetário muitas vezes associado, não puderam ser identificados. Isso se deve à inexistência de exploração mineral regular 
e legal dentro dos limites municipais da cidade, ocorrendo, entretanto, na Região Metropolitana onde há extração de água mineral, areias, argilas e granito, este último ocorrendo apenas no município de Macaíba.

Assim, observa-se que a geodiversidade de Natal é diversa e possível de ser encontrada em todas as regiões da cidade. Devido à sua extensão e variedade, a geodiversidade de Natal pode ser usada para meios científicos, culturais, esportivos e turísticos, de forma a promover, em conjunto, a divulgação das belezas naturais e culturais da cidade e das geociências, auxiliando o processo de geoconservação.

\section{REFERÊNCIAS}

ALMEIDA, F. F. M.; HASUI, Y.; BRITO NEVES, B. B.; FUCK, R. A. Províncias Estruturais Brasileiras. In: Simpósio de Geologia do Nordeste, 8, Campina Grande, Anais... Recife: SBG, 1977. p. 363-391.

BARbOSA, J. A.; LIMA FILHO, M. Os Domínios da Bacia da Paraíba. In: Congresso Brasileiro de P\&D em Petróleo e Gás, 3, Salvador, Anais... Disponível em CD-ROM, 2005.

BARRETO, A. M. F.; SUGUIO, K.; BEZERRA, F. H. R.; TATUMI, S. H.; YEE, M.; GIANNINI, P. C. F. Geologia e Geomorfologia do Quaternário Costeiro do Estado do Rio Grande do Norte. Geologia USP - Série Científica, São Paulo, v. 4, n. 2, p. 1-12, 2004.

BEZERRA, F. H. R.; AMARO, V. E.; VITA-FINZI, C.; SAADI, A. Pliocene-Quaternary fault control of sedimentation and coastal plain morphology in NE Brazil. Journal of South American Earth Sciences, v. 14, n. 1, p. 61-75, 2001.

BRILHA, J. Património Geológico e Geoconservação: a conservação da natureza na sua vertente geológica. $1^{\text {a }}$ ed. Braga: Palimage Editores, 2005. 183p.

CÓRDOBA, V. C.; JARDIM DE SÁ, E. F.; SOUSA, D. C.; ANTUNES, A. F. Bacia de Pernambuco-Paraíba. Boletim de Geociências da Petrobras, v. 15, n. 2, p. 391-403, 2007

CUNHA, E. M. S. Evolução atual do litoral de Natal-RN (Brasil) e suas aplicações a gestão integrada. 2004. 393 f. Tese (Doctorado de Ciencias del Mar) - Universitat de Barcelona, Barcelona, Barcelona, 2004.

DANTAS, M. E.; FERREIRA, R. V. Relevo. In: PFALTZGRAFF, P. A. S.; TORRES, F. S. M. Geodiversidade do Estado do Rio Grande do Norte. Recife: CPRM - Serviço Geológico do Brasil, 2010. Cap. 6, p. 77-92.

FISHER, B.; TURNER, R. K.; MORLING, P. Defining and classifying ecossystem services for decision making. Ecological Economics, v.68, n. 3, p. 643-653, 2009.

FONSECA, V. P.; SOUSA, M. O. L.; SILVA, F. O.; BEZERRA, F. H. R.; AMARAL, R. F.; SOUZA, Z. S.; FERREIRA, A. C.; DUTRA, R. R. Carta Geológica - Folha Natal (SB-25-V-CV), escala 1:100.00. Natal: CPRM - Serviço Geológico do Brasil, 2012. 
Galopim DE CARValho, A. M. Como Bola Colorida, a Terra, Património da Humanidade. $1^{\mathrm{a}}$ ed. Lisboa: Âncora Editora, 2007. 245p.

GRAY, M. Geodiversity: valuing and conserving abiotic nature. $1^{\text {a }}$ ed. Chichester: John Wiley \& Sons, 2004. 434p.

GRAY, M. Geodiversity: valuing and conserving abiotic nature. $2^{\mathrm{a}}$ ed. Chichester: John Wiley \& Sons, 2013. 495p.

LEI COMPLEMENTAR No 082, de 21 de junho de 2007. Dispõe sobre o Plano Diretor de Natal e dá outras providências. Diário Oficial do Município, Edição Especial nº 1169, Natal - RN.

MELO, A. C. C. Antropogeomorfologia da Cidade do Natal. 2013. 74 f. Monografia (Trabalho de Conclusão de Curso) - Departamento de Geologia, Universidade Federal do Rio Grande do Norte, Natal, 2013.

MOHRIAK, W. U. Bacias Sedimentares da Margem Continental Brasileira. In: BIZZI, L. A.; SCHOBBENHAUS, C.; VIDOTTI, R. M.; GONÇALVES, J. H. (eds.) Geologia, Tectônica e Recursos Minerais do Brasil. Brasília: CPRM - Serviço Geológico do Brasil, 2003. Cap. 3, p. 87 94.

MOCHIUTTI, N. F.; GUIMARÃES, G. B.; MELO, M. S. Os Valores da Geodiversidade na Região de Piraí da Serra, Paraná. Geociências UNESP, v. 30, n. 4, p. 651-668, 2011.

MOCHIUTTI, N. F.; GUIMARÃES, G. B.; MOREIRA, J. C.; LIMA, F. F.; FREITAS, F. I. Os Valores da Geodiversidade: Geossítio do Geopark do Araripe/CE. Anuário do Instituto de Geociências - UFRJ, v. 35, n. 1, p. 173-189, 2012.

NATURAL ENGLAND. Revealing the value of nature. $1^{\mathrm{a}}$ ed. Birminghan: W Lake, 2006, 38p.

OLIVEIRA, M. I. M.; BAGNOLI, E.; FARIAS, C. C.; NOGUEIRA, A. M. B.; SANTIAGO, M. Considerações sobre a geometria, petrografia, sedimentologia, diagênese e idades dos beachrocks do Rio Grande do Norte. In: CONGRESSO BRASILEIRO DE GEOLOGIA, 36, 1990, Natal. Boletim de Resumos... Natal: SBG, 1990. p. 621-634.

PEREIRA, R. G. F. A. Geoconservação e Desenvolvimento Sustentável na Chapada Diamantina (Bahia - Brasil). 2016. 318f. Tese (Doutorado em Ciências) - Escola de Ciências, Universidade do Minho, Braga, 2016.

SILVA, M.L.N. Geodiversidade da Cidade do Natal: Valores, Classificações e Ameaças. 2016. 170f. Monografia (Trabalho de Conclusão de Curso) - Departamento de Geologia, Universidade Federal do Rio Grande do Norte, Natal, 2016.

SOUZA, I. Nova História de Natal. $2^{\mathrm{a}}$ ed. Natal: Departamento Estadual de Imprensa, 2008. 800p.

Trabalho enviado em 02/11/2016

Trabalho aceito em 05/12/2016 